\title{
Participatory Design, beyond the local
}

$\begin{array}{ccc} & \text { Workshop } & \\ \text { M. Teli } & \text { P. Antoniadis } & \text { C. Bassetti } \\ \text { Madeira Interactive Technologies } & \text { NetHood } & \text { Zurich } \\ \text { Institute } & \text { Switzerland } & \text { University of Trento } \\ \text { Tunchal, Portugal } & \text { Trento, Italy } \\ \text { Italy } \\ \text { maurizio.teli@m-iti.org } & \text { panayotis@ @ethood.org } & \text { chiara.bassetti@ unitn.it } \\ \text { S. De Paoli } & \text { I. Apostol } & \\ \text { Abertay University } & \text { NetHood } & \text { G. Allegretti } \\ \text { Dundee } & \text { Zurich } & \text { Centre for Social Studies (CES) - } \\ \text { Scotland } & \text { University of Coimbra } \\ \text { S.DePaoli@ abertay.ac.uk } & \text { Coimbra, Portugal } \\ & \text { ileana @ nethood.org } & \text { giovanni.allegretti @ ces.uc.pt } \\ & \text { M. Secchi } & \\ & \text { Centre for Social Studies (CES) - } & \\ & \text { University of Coimbra } & \\ & \text { Coimbra, Portugal } & \\ & \text { michelangelo.secchi@ces.uc.pt } & \end{array}$

\begin{abstract}
${ }^{\mathbf{1}}$
This workshop aims at stimulating and opening a debate around the capacity of Participatory Design (PD) and other co-design approaches to deliver outcomes and methodologies that can have an impact and value for reuse well beyond the local context in which they were originally developed. This will be achieved by stimulating the submission of position papers by researchers from the PD community and beyond.These papers will be discussed during the workshop in order to identify challenges, obstacles but also potentials for scaling up PD processes and results from the local to the global.
\end{abstract}

\section{CCS CONCEPTS}

- Human-centered computing $\rightarrow$ Interaction design $\rightarrow$ Interaction design process and methods $\rightarrow$ Participatory design

\section{KEYWORDS}

Participatory Design, Scale, Processes, Outcomes, Collective Intelligence

\footnotetext{
${ }^{1}$ Permission to make digital or hard copies of part or all of this work for personal or classroom use is granted without fee provided that copies are not made or distributed for profit or commercial advantage and that copies bear this notice and the full citation on the first page. Copyrights for third-party components of this work must be honored. For all other uses, contact the Owner/Author. C\&T '17, June 26-30, 2017, Troyes, France (C) 2017 Copyright is held by the owner/author(s). ACM ISBN 978-14503-4854-6/17/06. http://dx.doi.org/10.1145/3083671.3083715

ACM Reference format:

M. Teli, P. Antoniadis P., C. Bassetti, S. De Paoli, I. Apostol, G. Allegretti, M. Secchi. 2017. Participatory Design, beyond the local. In Proceedings of the 8th International Conference on Communities and Technologies (C\&T '17), 4 pages. DOI: $10.1145 / 1234$

\section{WORKSHOP THEME}

Participatory Design (or simply PD) is by definition contextspecific and it is an open question how both the process of PD and its outcome can scale up and become relevant in different situations, beyond the local.

Participatory Design started in the 1970s in Scandinavian countries with local projects that had the ambition to affect technology development at the national level, like UTOPIA [5]. Since then, the processes and practices of PD have evolved and have moved well beyond the original Scandinavian tradition, focusing on projects taking place in different countries, targeting the workplace or the local community [1].

PD practices and methods, often referred to as co-design, have become part of the narratives and practices of many research and innovation projects, even involving institutional funding programs like the European Commission "Collective Awareness Platform for Sustainability and Social Innovation" [4] (CAPS). This program focuses on stimulating bottom-up processes of social 
innovation where the involvement of end-users and communities in shaping the direction of these same processes is fundamental. As much of the work of CAPS projects is to realize platforms (broadly defined to include web, mobile, IoT, etc.), the design of such platforms constitutes a relevant area for PD research and activities. In addition, as CAPS are targeted at different categories of European citizens on different themes (from urban accessibility to poverty and unemployment, passing through collective decision-making, wireless community networks, and many others), this calls for the capacity of the design to capture and harness diverse view points and needs. CAPS projects are characterized by the ambition of co-designing technological tools with a European-wide scope.

Projects like the CAPS, therefore, pose new questions to PD and, more generally, to any co-design endeavor. The main concern is probably the scalability of participatory practices and their results. How can PD processes and outcomes scale up and become relevant in different situations, beyond the local? How can PD activities and results impact the supra-national and supra-local level? How information and knowledge circulate beyond single, and often localized, communities of participants?

Indeed, there are ongoing efforts from researchers and practitioners to explore and try to answer these questions both in terms of processes and outcomes. On the one hand, we have the development of participatory design structured methodologies [1] or pattern languages [6]. These aim at generalizing the lessons learned from successful PD processes and making it easier for initiators and facilitators, in different environments, to take advantage of previous experiences, even if context-specific. On the other hand, another trend in $\mathrm{PD}$, often referred to as "infrastructuring" [3], aims to produce, through a single contextspecific PD process, tools that are not finalized outputs serving specific needs but that can provide the flexibility for the community to adapt the tool to their needs over time. By being more generic, and more flexible, such tools could be used in different situations and contexts, to serve the needs and desires of one specific community.

Following these two strategies (i.e., patterns and infrastructuring), it is clear that the scalability of PD could benefit from a much wider and solidified discussion on how the knowledge developed during PD processes, by practitioners, academics, and research participants, circulates among different local contexts, projects, institutions, and organizations (whether research-based or otherwise). In other words, there is a need to reflect on PD beyond the local, thereby stimulating the circulation of knowledge about the challenges and results of trials in this direction, and hence, developing a collective research agenda on the topic.

\section{WORKSHOP GOALS}

The overall objective of the workshop is to build a community of researchers and practitioners - working in the field of PD, interaction design and similar approaches - who are going beyond the local in their professional practice and wish to explore the limits and challenges of their activity through comparisons, critical analysis, and storytelling, with the desire to transcend their own disciplinary perspectives.

More specifically, in this workshop we would like to invite papers that can contribute to the discussion about PD beyond the local in different ways:

1) presenting success stories of knowledge circulation either in terms of processes or outcomes in PD and beyond;

2) discussing and consolidating a common grammar of PD between a variety of disciplinary viewpoints;

3) discussing theoretical aspects of the problem of knowledge circulation between different local contexts or different projects an avenue which may very well include Science and Technology Studies research experiences which could benefit PD;

4) discussing the problem of going beyond the local from disciplinary viewpoints as varied as software engineering, architecture, community informatics, urban planning, sociology, political sciences, anthropology, etc.

5) introducing novel PD projects and methodologies that try to achieve explicitly or implicitly the objective of going beyond the local;

6) comparing approaches and methodologies from different disciplinary perspectives.

As an outcome of this workshop, the organizers would like to collect the best contributions in a shared publication, whose venue will be identified collectively during the workshop.

\section{WORKSHOP ACTIVITIES}

The workshop activities will unfold over a full day, including four different time slots of about one and a half hours each. The morning will focus on the discussion by pre-assigned discussants of the accepted position papers, while the afternoon will focus on interactive activities oriented to the emergence of shared themes, methods, challenges and opportunities, as a way to identify a shared research agenda and potential funding schemes for PD beyond the local.

\section{MEANS OF SOLICITING AND SELECTING PARTICIPANTS}

The workshop's goals and call for (position) papers will form the basis of a web page hosted in the web sites of the different CAPS projects represented by the organizers. The call for papers will be distributed through various e-mailing lists, e.g. Pdworld, communities informatics, journal of peer production, Air-L, INURA. There will also be intense dissemination activity both inside the CAPS community and via external CAPS dissemination channels like CAPSSI, NGI4EU, and others. Additional solicitation will take place through online social media and the personal networks of the workshop organizers. 
Participants will be selected through the submission of position papers, which will be evaluated based on their relevance to the workshop goals and the diversity of perspectives that they bring.

Position papers (1-2 pages using the conference template) must be submitted by e-mail at participatory-design@capssi.eu. Submissions will be evaluated based on their relevance to the workshop goals and the diversity of perspectives that they bring.

\section{IMPORTANT DATES}

Early Submission deadline: 28 April 2017

Early Notification of Acceptance: 4 May 2017

Early-bird registration deadline: 5 May 2017

Late Submission Deadline: 30 May 2017

Late Notification of Acceptance: 5 June 2017

Workshop: 27 June 2017

\section{ACKNOWLEDGMENTS}

This workshop is partly supported by the EU Horizon 2020 (CAPS) projects PIE NEWS, no. 687922, EMPATIA, no. 687920, netCommons, no. 688768, and MAZI, no. 687953.

\section{ORGANIZERS BIO}

Maurizio Teli is assistant professor at the Madeira Interactive Technologies Institute. His research focuses on the transformations of participatory design in relation to contemporary capitalism. His most recent research project is the H2020 PIE News/Commonfare, rethinking welfare provision as a collaborative practice. He is going to act, together with Liesbeth Huysbrechts, as General Co-Chair of Participatory Design Conference 2018.

Panayotis Antoniadis is the co-founder of the Zurich-based nonprofit organization nethood.org. He has an interdisciplinary profile with background on the design and implementation of distributed systems (Computer Science Department, University of Crete), Ph.D. on the economics of peer-to-peer networks (Athens University of Economics and Business), post-doc on policies for the federation of shared virtualized infrastructures (UPMC Sorbonne Universites), and interdisciplinary research on the intersection of urban studies and computer science (ETH Zurich). Panayotis is currently active in the organization of various interdisciplinary events that aim to bring together researchers, practitioners, and activists from various fields around the participatory design of hybrid urban space with a focus on wireless and peer-to-peer technology.

Chiara Bassetti is senior research fellow at the Department of Information Engineering and Computer Science of the University of Trento, where she coordinates the H2020 PIE 3
News/Commonfare project, aimed at designing a digital platform to foster and support a novel collaborative form of welfare. Holding a $\mathrm{PhD}$ in sociology and social research, and a particular expertise in qualitative methods, since 2012 she works in interdisciplinary teams, contributing to the design of diverse tools and technologies. Starting next March, she will serve in the Managing Committe of the COST Action "From Sharing to Caring: Examining Socio-Technical Aspects of the Collaborative Economy".

Stefano De Paoli is Senior Lecturer in Sociology and Security Theme Research Leader at Abertay University in Scotland. Stefano works at the intersection of social sciences and design and has interests in the areas of reputation systems, cybersecurity and digital games. He is currently involved in the CAPS projects PIE News Commonfare.

Ileana Apostol (PhD in Urban Planning, University of Southern California) is a researcher of spatial production in the information age, and co-founder of the Zurich-based nonprofit nethood.org. For devising policy agendas to provide citizens the right to the hybrid city, she engages with interdisciplinary teams as well as with citizen action groups in Zurich that explore ways of living sustainably in the city. Before undertaking research on a full-time basis, Ileana has taught urban planning and design in the USA at California Polytechnic University, and at University of Southern California, and in Romania, at the University of Architecture and Urbanism, Bucharest.

Giovanni Allegretti is an architect, planner and senior researcher at the Centre for Social Studies of the Coimbra University, Portugal, where he coordinates the Ph.D "Democracy in the XXI century" and the "PEOPLEs' Observatory on Participation, Innovation and Local Powers". Expert of the European Commission for the URBACT Programme, he deals with Participatory Budgets and Interactive Planning since 1998. On this subject he wrote several books and essays and coordinated several international projects. Currently he is co-president of the Independent Authority for Promoting Participation of the Tuscany Region (Italy), for the mandate 2014-2019, and PI of the project EMPATIA funded by the EC under the Horizon 2020 Call: ICT2015/H2020-ICT-201, grant agreement n. 687920

Michelangelo Secchi is a junior research fellow at the Centre for Social Studies (CES) of Coimbra University, Portugal. He has been working for more than ten years as Public Sector consultant on the design and implementation of citizen engagement processes and participatory governance strategies. Recently he has been working as expert on stakeholder engagement in EU funded projects in the area of international development (EUROPEAID) and Smart Cities (National and Regional Structural Funds in Italy - PON REC Smart City). Since 2016 he is coordinating for CES the research activity of the CAPS project EMPATIA funded by the EC under Horizon 2020.

\section{REFERENCES}

[1] K. Bødker, F. Kensing, and J. Simonsen. 2004. Participatory IT design: designing for business and workplace realities. Cambridge, MA: MIT Press. 
[2] C. DiSalvo, A. Clement, and V. Pipek. 2012. Participatory design for, with, and by communities. In International Handbook of Participatory Design, J. Simonsen and T. Robertson (eds.). Routledge, Oxford, 182-209.

[3] H. Karasti. 2014. Infrastructuring in Participatory Design. In Proceedings of the 13th Participatory Design Conference: Research Papers - Volume 1 (PDC '14), 141-150. https://doi.org/10.1145/2661435.2661450

[4] F. Sestini. 2012. Collective Awareness Platforms: Engines for Sustainability and Ethics. IEEE TECHNOLOGY AND SOCIETY MAGAZINE, 54-62

[5] UTOPIA Project Group. 1981. The UTOPIA Project. On Training, Technology and Products Viewed from the Quality of Work Perspective

[6] D. Schuler, 2008. Liberating Voices: A Pattern Language for Communication Revolution. Cambridge, MA: MIT Press. 